\title{
Numerical Investigation of the Effect of Excess Air and Thermal Power Variation in a Liquid Fuelled Boiler
}

\author{
Bilal Sungur, Bahattin Topaloglu, Lutfu Namli, Hakan Ozcan \\ Mechanical Engineering Department, Ondokuz Mayis University \\ Samsun, Turkey \\ bilal.sungur@omu.edu.tr; btopal@omu.edu.tr; Inamli@omu.edu.tr; ozcanh@omu.edu.tr
}

\begin{abstract}
In this study, flame structures, boiler efficiency and exhaust gas temperatures were investigated numerically at different thermal power and excess air ratio in a liquid fuelled boiler. Calculations were carried out at two dimensional axisymmetric conditions and Fluent was used as the computational fluid dynamics software. In all studies, the standard k- $\varepsilon$ model was used for modelling the turbulent flow, the species transport model was used for modelling the combustion, and the pressurized swirl atomizer was used for modelling the injection. The calculations showed, that the droplet diameters after injection were reduced and droplets evaporated in a shorter period with increasing excess air. Exhaust gas temperatures were raised with the increasing boiler thermal power and excess air ratio. As expected, the higher flue gas temperature and excess air ratio showed lower boiler efficiency.
\end{abstract}

Keywords: Combustion, Numerical modelling, Diffusion flame, Boilers.

\section{Introduction}

Energy reserves are gradually being depleted and petroleum-based fuels damaging the environment, so researchers have turned to different quest. In this context, the importance of the efficient use of energy and interest in alternative fuels have increased. Boilers are defined as a closed vessel in which water or other fluid is heated by combustion of fuel and generally used in heating applications. The energy efficiency of boilers depends on combustion quality and the amount of energy transferred to the fluid. However, flue gas emissions depend on combustion quality, burner design, and the amount of contaminants in the fuel.

During combustion the mass, momentum and energy transfer occurs at the same time. In general, partial differential equations like continuity, momentum, energy and species transport can be solved with only numerical methods. In practice, many computational fluid dynamics software are available and FLUENT software is one of them.

For the combustion of liquid fuel, firstly the fuel comes into droplets, and then gasification and vaporization occurs. Therefore, fuel is sprayed by the pump into combustion air delivered by a fan or compressor. The fuel pre-heating may be needed in the case of high fuel viscosity. The obtained air-fuel mixture is ignited with an igniter (for example formation of sparks between the electrodes under high voltage). Various apparatuses were used in order to provide good mixing of the fuel with air, such as air rotator turbulators. These apparatuses also allow the stabilization of the flame. There are different burner types according to the purpose. Among these, high-pressurized fuel burners, air or steam blast burners, and rotary burners are the most known.

The heat of combustion is transferred to the fluid in the boiler and then this fluid transported to the space which needs heat. During the liquid fuel combustion, the flame is yellow-red colour because of the particle formation. Due to the long time necessary for combustion, the flame will be long. In order to be good and efficient combustion, heat and mass transfer must be good and so the total contact area of droplets must be as large as possible.

Saario et al. [1] investigated the heavy fuel oil combustion in the furnace experimentally and numerically. They used Fluent software for numerical simulation and they tried Standard k- $\varepsilon$ and Reynolds Stress Model (RSM) separately as turbulence model. The mixture fraction approach and the probability density function approach were used as combustion model. They said that predicted gas concentrations were in satisfactory agreement with measurement result, but they found that there were conflicting results near the burner and near the furnace axis. Ing et al. [2], analyzed the spray characteristics of biodiesel - diesel blends in different blend ratios, and made the comparison of these mixtures with pure diesel. In numerical study, they used Fluent software. As turbulence model k- $\varepsilon$ was used and they indicated that k- $\varepsilon$ model predicted 
the spray characteristics of all biodiesel blends successfully. Hosseini et al. [3] investigated the diesel-biodiesel fuel blends combustion and emission characteristics at a liquid fuelled boiler. They observed that biodiesel emitted less $\mathrm{CO}, \mathrm{CO} 2$ and particulate matter than diesel, but more $\mathrm{NO}_{\mathrm{x}}$ emission. They stated that the use of biodiesel could be useful in industrial processes. Hu [4] researched the liquid fuel combustion at different fluid spray burners, experimentally and numerically. He said that numerical results provided a good agreement with experimental results.

In this study, flame structures, boiler efficiency and flue gas temperatures were examined at different thermal power and excess air ratio $(\lambda)$ at a liquid-fuelled boiler, in two-dimensional and axially symmetric conditions.

\section{Materials and Methods}

Computational Fluid Dynamics, usually called as CFD, is a branch of fluid mechanics, which solves the problems with numerical methods and algorithms via a computer. Especially developments on the technology and computer science have increased the importance of CFD software in recent years. Using physical experiments to get essential engineering data for design can be expensive and time consuming. CFD simulations are relatively inexpensive and can be executed in a short period of time. In practice, many computational fluid dynamics software are available and FLUENT software is one of them. Fluent can solve many different processes such as heat transfer, fluid motion, particle motion, droplet motion and combustion with finite volume method [5].

Modelling of the movement of the gas phase was made by Eulerian perspective to solve the mass, momentum, and energy conservation equations for scalar variables. These differential equations were solved using appropriate boundary conditions on the problem. The general form of conservation equations are expressed as follows:

$$
\frac{\partial}{\partial t}(\rho \Phi)+\operatorname{div}\left(\rho v \Phi-\Gamma_{\Phi} \operatorname{grad} \Phi\right)=S_{\Phi}
$$

In this equation, $\Phi$ is the dependent variable, $\Gamma_{\Phi}$ is convection coefficient of $\Phi$, and $S_{\Phi}$ is the source term of $\Phi$ convection equation.

Modelling of the movement of the liquid phase was made by Lagrange perspective. As mentioned before, fuel is sprayed by the pump into combustion air delivered by a fan or compressor. A droplet spectrum with different velocity and droplet size are formed as a result of spraying. Due to different initial values, droplets track on different trajectories, heat and evaporate with different velocities, then mixed with air and burn. For the determination of droplet spectrum, Fluent offers dispersion models such as linear dispersion, and Rosin Rammler dispersion models. The motion of the gas and liquid phases are taken into account with successive iterations.

Combustion model, turbulence model and radiation model is necessary for the modelling combustion at Fluent software. In this study, species transport- eddy dissipation model was used as combustion model, standart k- $\varepsilon$ model was used as turbulence model, P1 approach model was used as radiation model. Liquid fuel was injected with pressure from the center of the burner. Calculations were made for 9 different situation with $30 \mathrm{~kW}, 35 \mathrm{~kW}, 40 \mathrm{~kW}$ boiler thermal power and $\lambda=1.1, \lambda=1.2$ and $\lambda=1.3$ excess air ratio. Injector spray pressures were adjusted to $6,8,10$ bars, respectively. Pressurized swirl atomizer injection model was used as injection type, injection half angle was given $30^{\circ}$ and injector diameter was given $0.4 \mathrm{~mm}$. Rosin-Rammler dispersion model was used for modelling the dispersion of droplets. $\mathrm{C}_{10} \mathrm{H}_{22}$ fuel was accepted as diesel fuel and the fuel viscosity was entered $0.0024 \mathrm{~kg} / \mathrm{m} \mathrm{s}$.

Schematic diagram of the reverse flame fire tube boiler was given in Figure 1. Air inlet conditions at the burner region and the mesh structure which was used in this study were given in Figure 2. This mesh has a total of approximately 200,000 cells. Also, more grid structures were tested to see the grid's effect on the solution. Very fine grid having constant edge lengths of $0.5 \mathrm{~mm}$ and coarser grid having constant edge lengths of $2 \mathrm{~mm}$ with 800,000 and 50,000 meshes, respectively, were also used for calculations. However, in these calculations with more grids, there were no meaningful changes in the results; consequently, all calculations were performed with the grid with 200,000 meshes. All surfaces in contact with water were defined as the wall with wall temperature of $353 \mathrm{~K}$. Exit zone was defined by the pressure outlet, and air inlet was defined by velocity inlet. 



Fig. 1: Schematic diagram of the boiler.

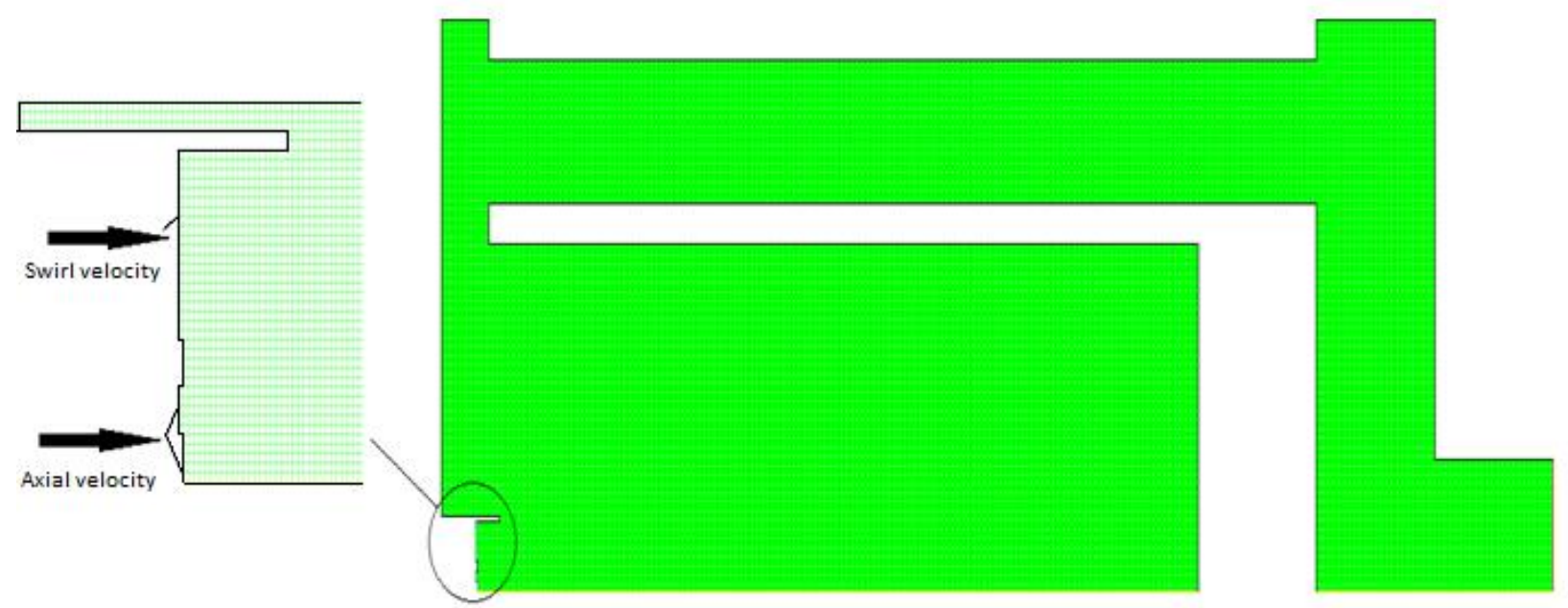

Fig. 2: The mesh structure of the boiler.

\section{Results and Discussions}

Figure 3 represents the change of the droplet diameters with the time at different $\lambda$. Maximum droplet diameters reduce with the increasing $\lambda$. In cases of $\lambda=1.1$ and $\lambda=1.3$ the maximum droplet diameters were approximately 82 micron and 73 micron, respectively. In addition, droplets evaporated in a shorter time with increasing $\lambda$, in the event of $\lambda=1.1$ and $\lambda=1.3$ the maximum droplet evaporated about $0.00925 \mathrm{~s}$ and $0.0062 \mathrm{~s}$, respectively. Because of the early evaporation, the maximum temperature level is higher and occurs in the region closer to the burner as shown in Figure 4.


Fig. 3: The change of the droplet diameters with the time. 
Figure 4 shows the temperature contours in the boiler at three thermal power and three $\lambda$. As shown in figure, in all cases the flame progressed along the flame tube, and then bumped to the rear surface of the flame tube, returned from there and directed towards the smoke pipe. Because of the flame tube and smoke tube surrounded with water, the heat of combustion is transferred to these regions. As shown in Figure 4, the maximum flame temperatures and the temperatures of the gas entering the smoke tubes increase with the rising boiler thermal power. Also with the increase of the $\lambda$, it was observed that the maximum flame temperature increased.

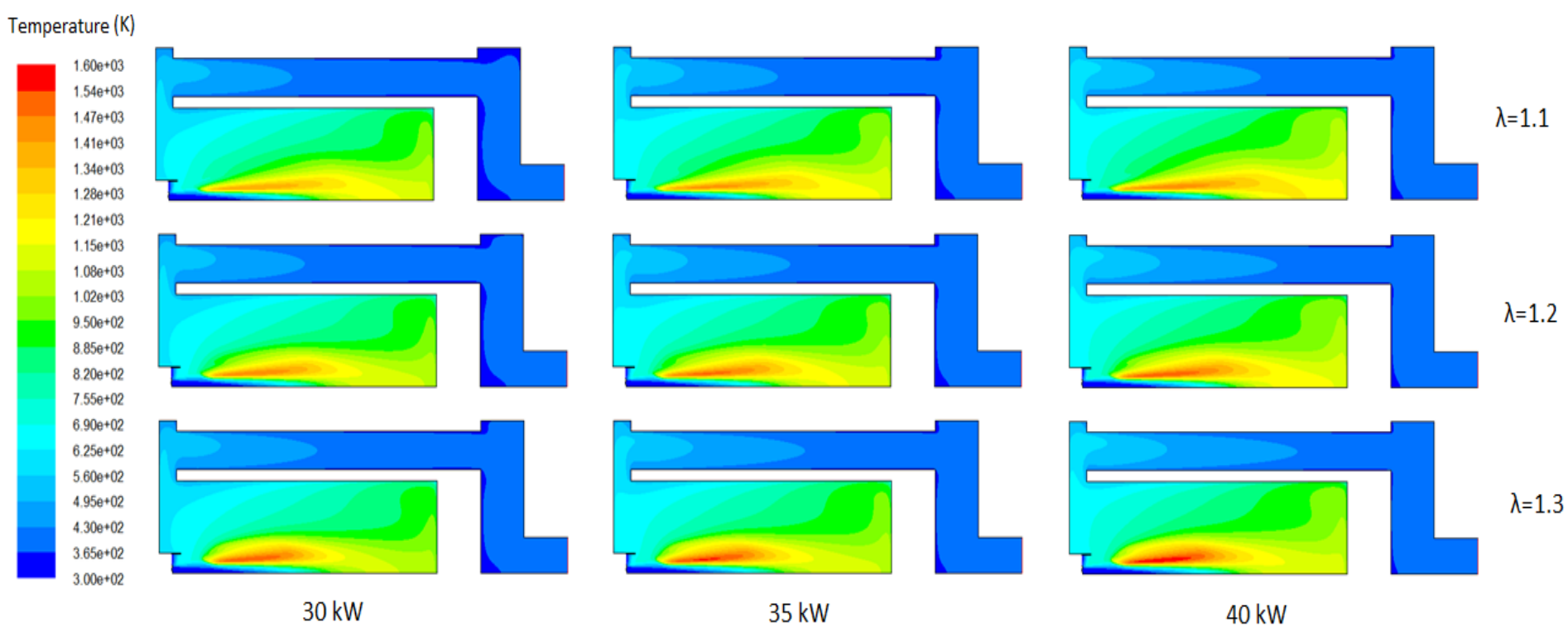

Fig. 4: The temperature contours in the boiler at different thermal power and $\lambda$.

In Figure 5, stream functions were given at different $\lambda$ for $35 \mathrm{~kW}$ boiler thermal power. As shown in Figure 5 flow progressed along the flame tube, turned back from there and directed to smoke tubes and lastly exited from the chimney.
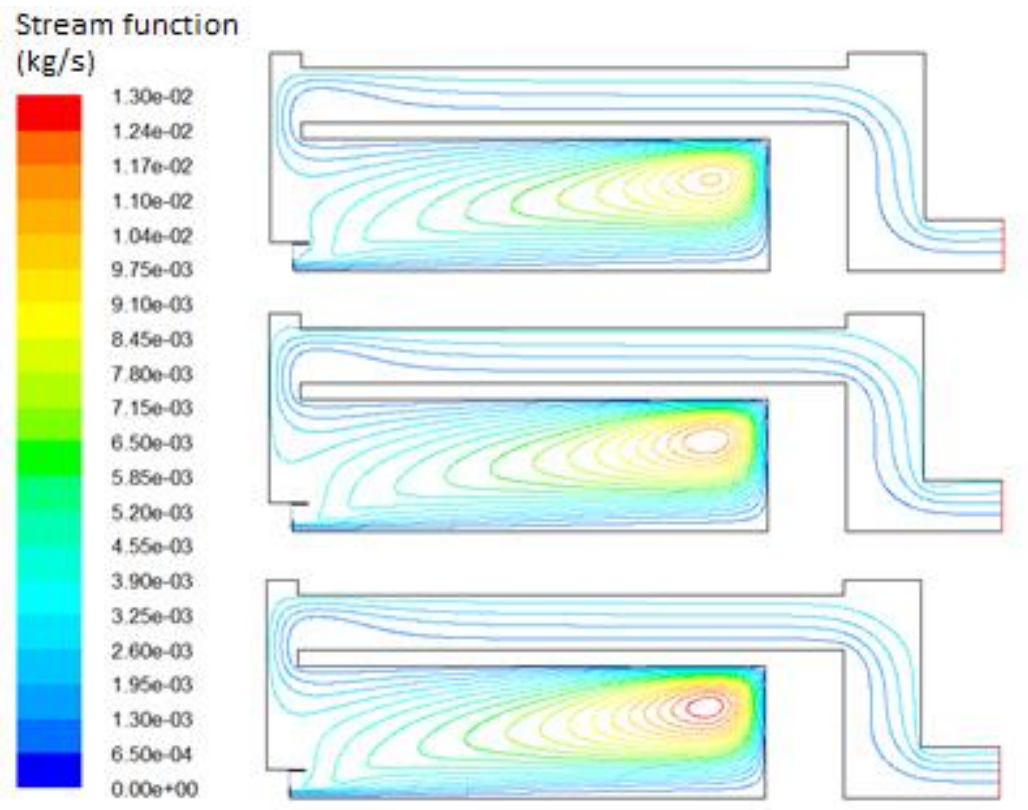

$\lambda=1.1$

$\lambda=1.2$

Fig. 5: Stream functions at different $\lambda$. 
Exhaust gas temperatures at different $\lambda$ and at different thermal power were given in Figure 6. Exhaust gas temperatures increased slightly with increasing $\lambda$. This situation seems like the opposite of expected, but it can be noted that there is no much difference between the outlet temperatures. Also increasing the thermal power increased exhaust temperatures. Comparing the $30 \mathrm{~kW}$ and $40 \mathrm{~kW}$ thermal power, it was observed that flue gas temperatures vary from approximately 10 to $20 \mathrm{~K}$ depending on the $\lambda$.

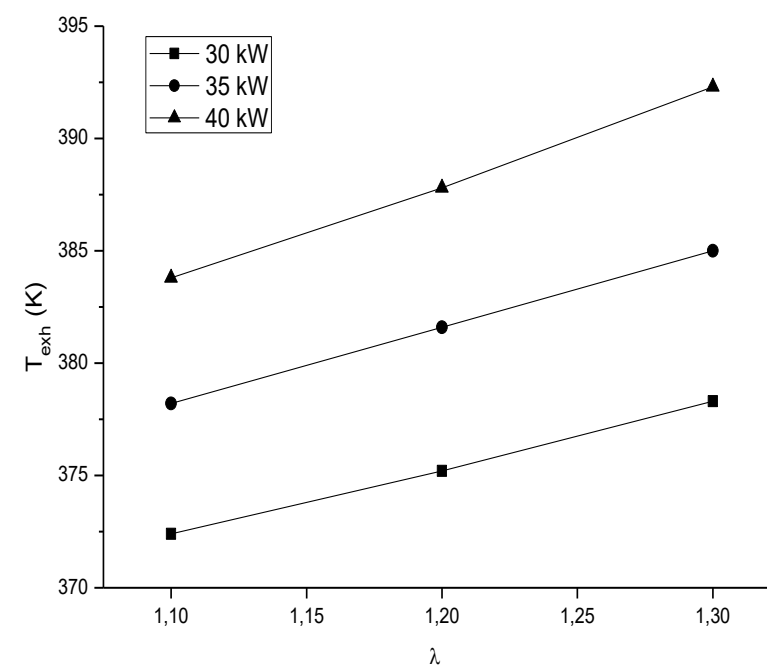

Fig. 6: Exhaust gas temperatures at different $\lambda$ and at different thermal power.

Comparison of the boiler efficiencies was given in Figure 7. As can be seen, increasing boiler thermal power and $\lambda$, decrease the boiler efficiency. According to this situation, the highest boiler efficiency was obtained in the case of $30 \mathrm{~kW}$ and $\lambda=1.1$, and the lowest boiler efficiency was obtained in the case of $40 \mathrm{~kW}$ and $\lambda=1.3$.

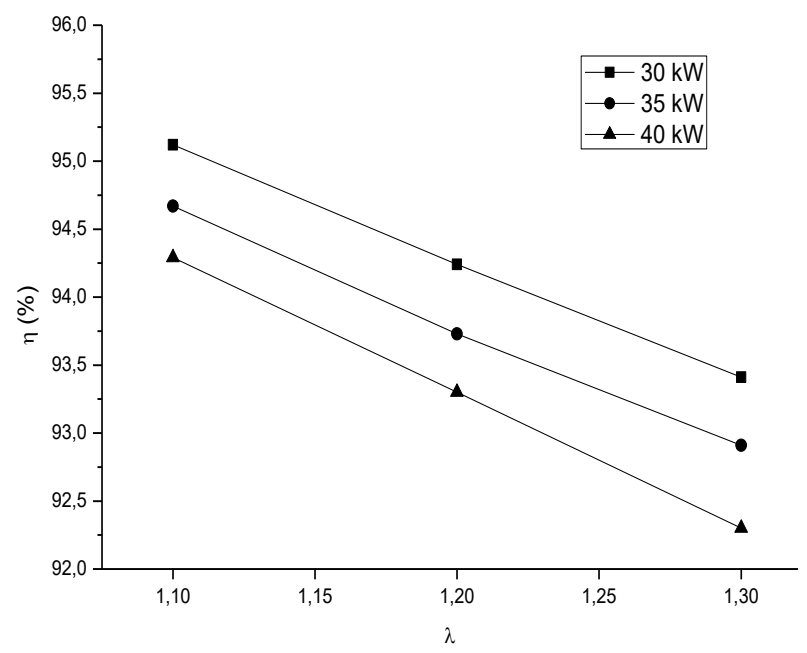

Fig. 7: Boiler efficiencies.

\section{Conclusion}

In this study a liquid fuelled boiler was modelled at two-dimensional conditions with three different thermal powers and three different $\lambda$. Maximum droplet diameters reduced with the increasing $\lambda$ which reduced the evaporation and burning time. As a consequence, the maximum temperature became higher and occurred in the region closer to the burner. Increasing the thermal power increased the combustion temperatures and the exhaust temperatures, which caused a decrease at boiler efficiency, as expected. 


\section{References}

[1] A. Saario, A. Rebola, P. J. Coelho, M. Costa, and A. Oksanen, "Heavy fuel oil combustion in a cylindrical laboratory furnace: measurements and modelling," Fuel, vol. 84, pp. 359-369, 2005.

[2] N. L. Ing, M. N. M. Jaafar, M. S. A. Ishak, and M. A. A. Arizal, "Spray characteristic of palm biofuel blends," International Journal of Mechanical and Materials Engineering, vol. 5, pp. 214-221, 2010.

[3] B. S. Hosseini, K. Bashirnezhad, A. R. Moghiman, Y. Kharzaii, and N. Nikoofal, "Experimental comparison of combustion characteristic and pollutant emission of gas oil and biodiesel," International Journal of Mechanical and Materials Engineering, vol. 1, no. 1, 2010.

[4] D. Hu, "Comparison of numerical and experimental results of four liquid spray combustors," Master Thesis, Dept. Mech. Eng., Louisiana State Univ., USA, 2002.

[5] Fluent 6.3, "Fluent User's Guide," 2006. 